- Clinical Research •

\title{
Meta-analysis of selective defunctioning stoma in low anterior resection
}

\author{
Pei-Rong Ding ${ }^{1,2}$, Xin An ${ }^{1,3}$, Zhi-Zhong Pan ${ }^{1,2}$, De-Sen Wan ${ }^{1,2}$, \\ Yu-Jing Fang ${ }^{1,2}$, Xiao-Jun $\mathrm{Wu}^{1,2}$, Li-Ren $\mathrm{Li}^{1,2}$ and Zhen-Hai $\mathrm{Lu}^{1,2}$
}

1. State Key Laboratory of Oncology in South China,

Guangdong, Guangzhou, 510060,

P. R. China

2. Department of Colorectal Surgery,

Sun Yat-sen University Cancer Center,

Guangzhou, Guangdong, 510060,

P. R. China

3. Department of Medical Oncology,

Sun Yat-sen University Cancer Center,

Guangzhou, Guangdong, 510060 ,

P. R. China

Correspondence to: Zhi-Zhong Pan

Tel. : 86.20.87343124

Email : panzhzh@mail.sysu.edu.cn

Grants : Science and Technology

Planning Project of Guangdong Province

(No.2008B030301119); Medical

Scientific Research Foundation of

Guangdong Province (No. B2008057)

This paper was translated into English from its original publication in Chinese.

Translated by: Zhong-Guo Zhou

and Hua He on 2009-08-07

The original Chinese version of this paper is published in:Ai Zheng (Chinese Journal of Cancer) 28(7);http://www.cjesysu.cn/cn/ article.asp?id=15667 )

Submitted: 2008-12-08

Revised: 2009-01-02
[Abstract] Background and Objective: Whether selective defunctioning stoma could reduce the rate of anastomotic leak and lessen adverse effects in low anterior resection (LAR) remains controversial. This study was to evaluate the necessity of selective defunctioning stoma after LAR. Methods: Medline databases were searched and English-language articles regarding to selective defunctioning stoma in LAR published from January 1, 1990 to October 1, 2007 were acquired. Seven literatures from seven different studies were included in this study, with total enrollment of 5040 patient. The rate of anastomotic leakage and re-operation rate in different surgical procedures (with or without selective defunctioning stoma) were pooled to compare using meta-analysis. Results: Selective defunctioning stoma did not significantly reduce the rate of anastomotic leakage after LAR. The pooled odds ratio (OR) was $0.68(95 \% \mathrm{Cl}=0.45-1.02, \quad P>0.05)$. Selective defunctioning stoma significantly reduced the rate of surgery-required anastomotic leakage following LAR. The pooled OR was $0.33(95 \% \mathrm{Cl}=0.25-$ $0.44, P<0.01)$. Conclusion: Although selective defunctioning stoma does not reduce the rate of anastomotic leakage, it reduces the rate of surgeryrequired anastomotic leakage.

Key words: rectal neoplasm, low anterior resection, selective defunctioning stoma, anastomotic leakage, meta-analysis

The incidence of colorectal cancer is increasing in China. Rectal cancer accounts for about $50 \%$ of all the colorectal cancers, most of which are middle and low rectal cancer. ${ }^{1}$ Due to the anatomic characteristic of pelvic cavity, rectal cancer shows many limits in the area of surgical ablation, which influences the treatment effectiveness. Total mesorectal excision (TME) has greatly improved the rate of anus-preserving and decreased the local recurrent rate for low rectal cancer, but increased the risk of anastomostic leakage. Anastomostic leakage may result in a series of complications: pelvic abscess, septic shock, even death. Patients with anastomostic leakage seem to have much higher incidence of recurrence, and unfavorable prognosis. Therefore, in order to decrease the incidence and severity of anastomostic leakage, many researchers have tried to apply prophylactic stoma of ileum or colon in the proximal end of stomas. However, the effect of prophylactic stoma on the low 
anterior resection (LAR) of rectal cancer is still controversial. In this study, we applied meta-analysis to explore the impact of selective defunctioning stoma on LAR In decreasing the incidence and the severity of postoperative anastomostic leakage.

\section{Data and Materials}

Data collection. MedLine databases, Chinese Biomedical Literature Database, China Journal Network were searched and articles regarding to selective defunctioning stoma in LAR published from January 1, 1990 to October 1, 2007 were acquired. Subject headings and key words including rectal cancer, low anterior resection, anastomostic leakage, defunctioning (both in English and Chinese), were filled as the search item.

Inclusion criteria. The inclusion criterion of literatures were as follows: (1) literatures published between 1990 to October of 2007 regarding the impact of selective defunctioning stoma in LAR; (2) the operation type was LAR; (3) the patients receiving LAR only were classified into the control group, and the patients undergoing LAR following prophylactic stoma of ileum or colon were classified into the experimental group;

(4) the patients were pathologically confirmed;

(5) if there were many groups in the clinical trials, only two needed groups were chosen; (6) if there were more than one published papers out of the same clinical trail, only the recently pub- lished one was chosen; (7) all the literatures must be screened by more than two clinicians, and examined by statisticians.

Exclusion criteria. The inclusion criterion of literatures was as follows: (1) literatures of clinical trails included patients with benign diseases; (2) literatures in which some of the operation methods was not LAR; (3) literatures in which the data about the rate of anastomostic leakage were incomplete; (4) literatures in which the case number was less than 100 .

Statistical analysis. Software of RevMan 4.2 supplied by http://www.cochrane.org was used for analysis.

The OR value model was chosen according to the result of heterogeneity tests. $p>0.05$ means there is no significant difference between studies, and all the studies were combined by the fixed effect model. If $\mathrm{p}<0.05$, the random effect model was used.

\section{Results}

Results of date collection. Twelve papers were found published between 1997 to 2007 regarding to the subject, and only seven papers met the criteria..$^{2-8}$ In total 5040 cases were included in the analysis as shown in Table 1.

Result of meta-analysis. Meta-analysis of the impact of selective defunctioning stoma on anastomotic leakage in LAR. The heterogeneity test was used to analyze datum in Table $2(\mathrm{p}=0$. $03<0.05$ ), and the random effect model was also

Table 1 Original articles included in the meta-analysis

\begin{tabular}{|c|c|c|c|}
\hline Study & Authors & Origin & Title \\
\hline 1 & Dehni et al. ${ }^{[2]}$ & $\begin{array}{l}\text { Br J Surg, } 1998,85(8): \\
1114-1117 .\end{array}$ & $\begin{array}{l}\text { Influence of a defunctioning stoma on leakage rates after low colorectal anastomosis } \\
\text { and colonic J pouch-anal anastomosis }\end{array}$ \\
\hline 2 & Gastinger et al. ${ }^{[3]}$ & $\begin{array}{l}\text { Br J Surg, } 2005,92(9) \text { : } \\
1137-1142 .\end{array}$ & Protective defunctioning stoma in low anterior resection for rectal carcinoma \\
\hline 3 & Law et al. ${ }^{[4]}$ & $\begin{array}{l}\text { Am J Surg, } 2000,179(2): \\
92-96 .\end{array}$ & $\begin{array}{l}\text { Risk factors for anastomotic leakage after low anterior resection with total mesorectal } \\
\text { excision }\end{array}$ \\
\hline 4 & Machado et al. ${ }^{[5]}$ & $\begin{array}{l}\text { Dis Colon Rectum, 2002,45 } \\
\text { ( } 7): 940-945 .\end{array}$ & $\begin{array}{l}\text { Defunctioning stoma in low anterior resection with colonic pouch for rectal cancer: a } \\
\text { comparison between two hospitals with a different policy }\end{array}$ \\
\hline 5 & Marusch et al. ${ }^{[6]}$ & $\begin{array}{l}\text { Dis Colon Rectum, 2002,45 } \\
\text { (9):1164-1171. }\end{array}$ & Value of a protective stoma in low anterior resections for rectal cancer \\
\hline 6 & Ronnie et al. ${ }^{[7]}$ & $\begin{array}{l}\text { World J Surg, } 1999,23(5) \text { : } \\
\text { 463-467; discussion 467-468. }\end{array}$ & $\begin{array}{l}\text { Prospective evaluation of selective defunctioning stoma for low anterior resection with } \\
\text { total mesorectal excision }\end{array}$ \\
\hline 7 & Wong et al. ${ }^{[8]}$ & $\begin{array}{l}\text { Dis Colon Rectum, 2005,48 } \\
\text { (11) 2076-2079. }\end{array}$ & $\begin{array}{l}\text { A defunctioning ileostomy does not prevent clinical anastomotic leak after a low } \\
\text { anterior resection: a prospective, comparative study }\end{array}$ \\
\hline
\end{tabular}


used (Fig. 1). The studies in groups 2, 4,5,6,7 showed that the $95 \%$ confidence interval $(95 \%$ $\mathrm{CI})$ of datum was across the ineffective line, and selective defunctioning stoma did not significantly influence the incidence of anastomotic leakage in LAR. $95 \% \mathrm{CI}$ of datum of odds ratio (OR) in groups 1,3 was located on the left of the ineffective line, showing that the impact of selective defunctioning stoma on anastomotic leakage in LAR was statistically significant. In the study, 2168 out of 5040 cases received LAR and selective defunctioning stoma, and 2872 out of 5040 cases received LAR only. The pooled OR of the groups of selective defunctioning stoma was $0.68,95 \% \mathrm{CI}$ of which was $(0.45,1.02)$ and was across the ineffective line, showing no statistical significance. Selective defunctioning stoma did not have a prophylactic effect on the occurrence of anastomotic leakage in LAR.

Sensitivity analysis was performed to detect the robustness of meta-analysis. The method of excluding the group data of the lowest weight and the changing effect model were used to test. The results of two sensitivity analyses were consistent, indicating that this study was comparatively robust (Table 3 ).
Meta-analysis of the impact of selective defunctioning stoma on surgery-required anastomotic leakage after LAR. The heterogeneity test was employed to analyze datum in Table $4(\mathrm{p}=0.36>0.05)$, and the fixed effect model was used to analyze (Fig. 2). The studies in groups 2 and 6 showed that 95\% CI of datum were across the ineffective line, implying that the impact of selective defunctioning stoma on the happening of surgery-required anastomotic leakage after LAR was no significant. $95 \% \mathrm{CI}$ of datum of OR in groups 1,2,3,5 and 7 were located on the left of

Table 2 Impact of selective defunctioning stoma on anastomotic leakage after low anterior resection

\begin{tabular}{lcccccc}
\hline \multirow{2}{*}{ Study ID } & \multicolumn{2}{c}{ Defunctioning (cases) } & & \multicolumn{2}{c}{ Non-defunctioning } & (cases) \\
\cline { 2 - 3 } \cline { 5 - 6 } \cline { 5 - 6 } & Anastomotic leakage & Total & & Anastomotic eakage & Total \\
\hline Dehni & 13 & 152 & & 18 & 106 \\
Ronnie & 2 & 61 & & 11 & 87 \\
Marusch & 16 & 148 & & 35 & 334 \\
Law & 5 & 103 & & 15 & 93 \\
Machado & 6 & 81 & & 11 & 80 \\
Gastinger & 128 & 881 & & 262 & 1848 \\
Wong & 28 & 742 & & 13 & 324 \\
\hline
\end{tabular}

\begin{tabular}{|c|c|c|c|c|c|}
\hline \multirow{5}{*}{$\begin{array}{l}\text { Revicw: } \\
\text { Comparizon: } \\
\text { Outcome: } \\
\text { Study } \\
\text { or sub-category } \\
\end{array}$} & \multirow{2}{*}{\multicolumn{5}{|c|}{ 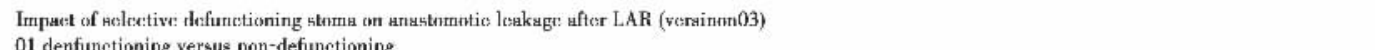 }} \\
\hline & \multirow{2}{*}{\multicolumn{5}{|c|}{$\begin{array}{l}01 \text { denfunctioning versus non-defunctioning } \\
\text { o1 Anaatomntic leak rate }\end{array}$}} \\
\hline & & & & & \\
\hline & Treatmet (1)efunct) & Control (Non-defunet) & \multirow{2}{*}{$\begin{array}{l}\text { OH (random) } \\
95 \% \mathrm{CI}\end{array}$} & Weight. & $O H($ randnm) \\
\hline & $u / N$ & $\mathrm{u} / \mathrm{N}$ & & $\%$ & $95 \% \mathrm{CI}$ \\
\hline Dethni & $13 / 152$ & $18 / 106$ & $\longrightarrow$ & 14.38 & $0.46[0.21,0.98]$ \\
\hline Ronnie & $2 / 61$ & $11 / 87$ & $\longleftrightarrow$ & 5.55 & \multirow{2}{*}{$\begin{array}{l}0.23[0.05,1.10] \\
1.04[0.05,1.94]\end{array}$} \\
\hline Mamusch & $16 / 148$ & $35 / 334$ & \multirow[b]{2}{*}{$\longmapsto$} & 17.25 & \\
\hline Law & $5 / 103$ & $15 / 93$ & & 9.79 & $0.27[0.09,0.76$ \\
\hline Machado & $6 / 81$ & $11 / 80$ & $\longrightarrow-$ & 9.89 & $0.50[0.18 .1 .43]$ \\
\hline Gratinger & $128 / 881$ & $262 / 1848$ & & 26.90 & $1.03[0.82 .1 .29]$ \\
\hline Fong & $28 / 742$ & $13 / 324$ & & 16.24 & $1.94[0.48,1.84]$ \\
\hline Totul $(95 \% \mathrm{CI})$ & 2168 & 2872 & & 100.00 & $0.68[0.45,1.02]$ \\
\hline \multicolumn{6}{|c|}{ Total events: 198 (Treatment (Defunet)). 365 (Control (Non-defunet)) } \\
\hline \multicolumn{6}{|c|}{ Test for heterogeneity: $\mathrm{Chi} ?=13.84, \mathrm{df}=6(\mathrm{P}=0,03), 1 ?=56.7 \%$} \\
\hline \multicolumn{6}{|c|}{ Tent for twer all effect: $\mathrm{Z}=1.88(R=0.06)$} \\
\hline
\end{tabular}

Figure 1 Impact of selective defunctioning stoma on anastomotic leakage after low anterior resection

Table 3 Sensitivity analysis for impact of selective defunctioning stoma on anastomotic leakage after low anterior resection

\begin{tabular}{lcccr}
\hline Item & $\begin{array}{c}\text { Defunctioning Anastomotic } \\
\text { leakage (cases) }\end{array}$ & $\begin{array}{c}\text { Non-defunctioning } \\
\text { Total (cases) }\end{array}$ & $\begin{array}{c}\text { Heterogeneity test } \\
P \text { value }\end{array}$ & $\begin{array}{c}\text { Effect model } \\
\text { Random }\end{array}$ \\
\hline Exclusion of Ronnie's group & $2107 / 4892$ & $2785 / 4892$ & 0.05 & $0.74(0.50,1.08)$ \\
Change effect model & $2168 / 5040$ & $2872 / 5040$ & 0.03 & $0.87(0.72,1.06)$ \\
\hline
\end{tabular}




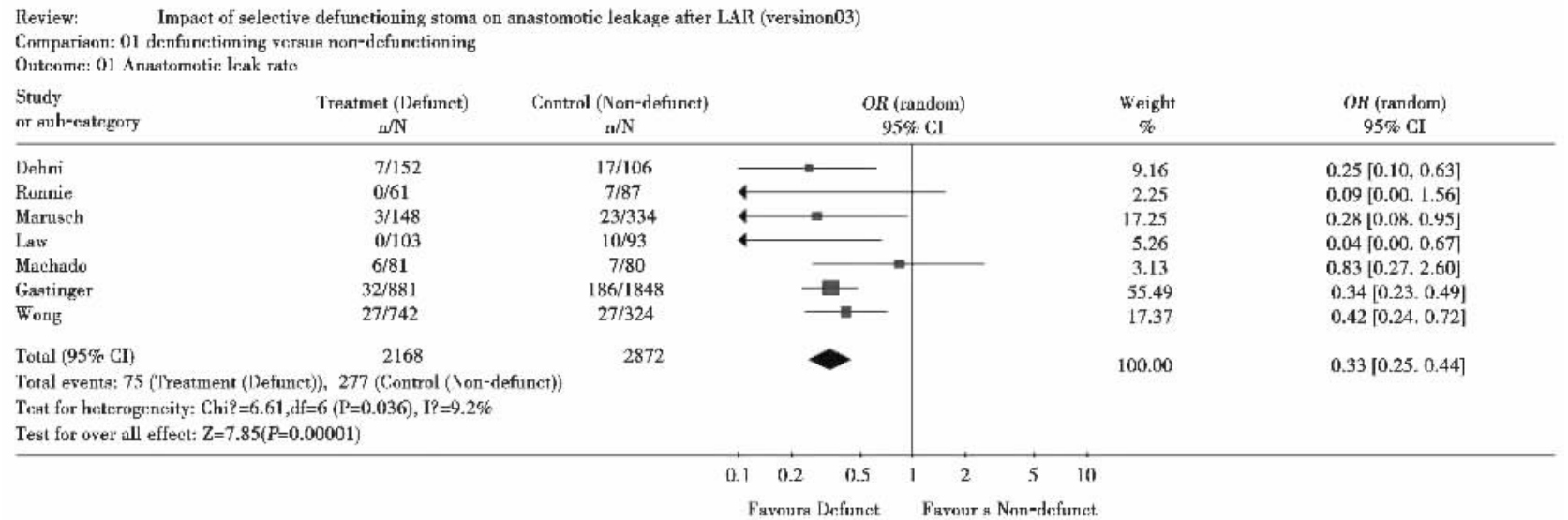

Figure 2 Impact of selective defunctioning stoma on surgery-required anastomotic leakage after low anterior resection

the ineffective line, suggesting that the impact of selective defunctioning stoma on surgery-required anastomotic leakage after LAR had statistical significance. Selective defunctioning stoma had a prophylactic effect on the happening of surgery-required anastomotic leakage after LAR. The pooled OR of the groups of selective defunctioning stoma was $0.33,95 \% \mathrm{CI}$ of which was $(0.25,0.44)$ and was located on the left of the ineffective line, with statistical significance. We asserted that selective defunctioning stoma had a prophylactic effect on the happening of surgery-required anastomotic leakage after LAR, and could decrease the severity of anastomatic

Table 4 Impact of selective defunctioning stoma on surgery-required anastomotic leakage after low anterior resection

\begin{tabular}{lccccc}
\hline \multirow{2}{*}{ Study ID } & \multicolumn{2}{c}{ Defunctioning (cases) } & & \multicolumn{2}{c}{ Non-defunctioning } \\
\cline { 2 - 3 } \cline { 5 - 6 } & $\begin{array}{c}\text { Surgery-required } \\
\text { anastomotic leakage }\end{array}$ & Total & & $\begin{array}{c}\text { Surgery-required } \\
\text { anastomotic leakage }\end{array}$ & Total \\
\hline Dehni & 7 & 152 & 17 & 106 \\
Ronnie & 0 & 61 & 7 & 87 \\
Marusch & 3 & 148 & 23 & 334 \\
Law & 0 & 103 & 10 & 93 \\
Machado & 6 & 81 & 7 & 80 \\
Gastinger & 32 & 881 & & 186 & 1048 \\
Wong & 27 & 742 & & 27 & 324 \\
\hline
\end{tabular}

leakage.

The method of excluding the group data of the lowest weight and the changing effect model were used to test. The test result showed that the results of two sensitivity analyses were consistent, which indicated that the conclusion of this study is comparatively robust (Table 5).

\section{Discussion}

Meta-analysis is one of statistical methods that is used to compare and synthesize the studies focusing on the same scientific problem. Different from simplex cases merging, meta-analysis requires not only the sample size but also the study design. Meta-analysis evaluates the total effect on the existent studies according to certain standards, and provides reliable evidence to help make clinical decisions.

With the changing of the life pattern, the incidences of carcinomas of the colon and rectum are increasing. Different from Western countries, the ratio of rectal cancer of China accounts for $50 \%$ among colon and rectal carcinomas, $80 \%$ of which are located at the middle or distal end. Nowadays, with the general practice of total mesorectal excision to operate the rectal cancer, the local recurrence rate of rectal cancer is

Table 5 Sensitivity analysis for impact of selective defunctioning stoma on surgery-required anastomotic

leakage after low anterior resection

\begin{tabular}{lcccr}
\hline Item & $\begin{array}{c}\text { Defunctioning Surgery-required } \\
\text { anastomotic leakage (cases) }\end{array}$ & $\begin{array}{c}\text { Non-defunctioning } \\
\text { Total (cases) }\end{array}$ & Heterogeneity test & Effect model \\
& $2107 / 4892$ & $2785 / 4892$ & 0.34 & value \\
\hline Exclusion of Ronnie's group & $2168 / 5040$ & $2872 / 5040$ & 0.36 & $0.34(0.26,0.45)$ \\
Change effect model & random & $0.35(0.25,0.48)$ \\
\hline
\end{tabular}


significantly reduced, but this brings the risk of anastomotic leakage increase. It was reported that the incidence of anastomotic leakage after the total mesorectal excision reached 6\%-22\%. ${ }^{14}$ Anastomotic leakage is one of the severe complications, and it could lead to a high mortality of $6.3 \%$ and permanent defunctioning stoma of $25 \%$. Meanwhile, patients with anastomotic leakage have higher postoperative recurrence risk and a lower survival rate. ${ }^{10,15-17}$ Patients with mild anastomotic leakage may be treated by conservative therapies, such as intensive drainage and anti-infection. However, most of the patients with anastomotic leakage need to be treated by re-operation of debridement draining and defunctioning stoma to rechannel stool drainage. Researchers have tried many methods to reduce the severity of anastomotic leakage, such as preoperative bowel preparation, pelvic drainage, and selective defunctioning stoma. The first two methods have been examined by meta-analysis to be useless in reducing the incidence of anastomotic leakage..$^{18-20}$ Nevertheless, the impact of selective defunctioning stoma is controversial. Whether the patient should receive selective defunctioning stoma is evaluated by clinicians according to the patients specific condition. Selection criteria include elder, patients with high medical risks (such as severe heart disease, diabetes mellitus, hyperthyreosis, hypoproteinemia, severe anemia, poor general physical condition or treated by steroid homones), intestinal obstruction, pelvic dissection complex, obesity, intraoperative hemorrhoea, ultra-low anastomosis, poor blood supply of anastomotic intestinal canal, high-tension of anastomtic stoma, imperfect intestinal ring excised by anastomat, ositive air test, and preoperative pelvic irradiative condition. 28

Law et $a l .^{4}$ claimed that selective defunctioning stoma plays an important role in LAR of rectal cancer and should be applied widely, because it can not only prevent anastomotic leakage after LAR, but also alleviate the severity and reduce the incidence of surgery-required anastomotic leakage and mortality. Gastinger et al., ${ }^{3}$ Marusch et al., ${ }^{6}$ and Wong et al. ${ }^{8}$ claimed that selective defunctioning stoma is not helpful to prevent anastomotic leakage after LAR, but can reduce the incidence of surgery-required anastomotic leakage. Machado et $\mathrm{al}^{5}$ and Ronnie et al. ${ }^{7}$ reported that selective defunctioning stoma cant neither prevent anastomotic leakage after LAR, nor alleviate the severity.

Selective defunctioning stoma has many disadvantages. It adds economic and psychological burdens to patients. Additionally, it causes many inherent complications, including anastomotic stricture, anastomotic leakage, complications from defunctioning stoma, permanent defunctioning stoma and a mortality rate of $0.5 \% .^{15,21-24}$ Different selections and different views of clinicians may lead to different or even severe impacts on patients. In order to provide more reliable evidence, we searched seven studies and carried out this meta-analysis. ${ }^{2-8}$

This study used the incidence of anastomotic leakage and surgery-required anastomotic leakage which reflect the severity of leakage as outcome variables. Concerning the role of selective defunctioning stoma in preventing anastomotic leakage, studies of groups 1,3 suggest that selective defunctioning stoma can decrease the risk of anastomotic leakage after LAR. Studies of groups $2,4,5,6,7$ suggest that selective defunctioning stoma has no statistical impact on decreasing anastomotic leakage. After meta-analysis, we found that selective defunctioning stoma does not significantly reduce the rate of anastomotic leakage after LAR. The OR was 0.68 (95\% CI=0.45-1.02, $\mathrm{p}>0.05)$. Meanwhile, concerning the impact of selective defunctioning stoma on the severity of anastomotic leakage, the studies of groups 1,2,3, 5 alleges that selective defunctioning stoma significantly reduces the rate of surgery-required anastomotic leakage following LAR, that is, selective defunctioning stoma has a prophylactic effect on the happening of surgery-required anastomotic leakage after LAR, and could decrease the severity of anastomatic leakage. The studies of groups 4,6 alleges that selective defunctioning stoma does not significantly reduce the rate of surgery-required anastomotic leakage after LAR. Our meta-analysis shows that 
selective defunctioning stoma significantly reduces the rate of surgery-required anastomotic leakage following LAR. The pooled OR is 0.33 (95\% CI $=0.25-0.44, \mathrm{p}<0.00001)$. In summary, although selective defunctioning stoma does not reduce the rate of anastomotic leakage, it reduces the rate of surgery-required anastomotic leakage.

In conclusion, the original intention of preventive colonic defunctioning stoma is to rechannel stool to make the distal end of anastomotic stoma comparatively "clean" and low-pressure, more importantly, to prevent the happening of anastomotic leakage. However, this method could not decrease the risk of anastomotic leakage, hence can not prevent anastomotic leakage most of the time. Once anastomotic leakage happens, preventive stoma may decrease some risk and damage to patients. According to the outcome of this study, selective defunctioning stoma could decrease the incidence and the severity of surgery-required anastomotic leakage. In a word, it still has some practical value for patients with the risk of anastomotic leakage. The defects of this study are: (1) limited by medical ethics, all studies enrolled were not randomized controlled trials; (2) due to publication bias, authors were reluctant to publish negative results or results leading to no conclusions. Therefore, the conclusion still needs large scale and multicentre clinical trials to verify.

\section{References}

[1] Parkin DM, Bray F, Ferlay J, et al. Global cancer statistics, $2002[J]$. CA Cancer J Clin, 2005,55(2):74-108.

[2] Dehni N, Schlegel RD, Cunningham C, et al. Influence of a defunctioning stoma on leakage rates after low colorectal anastomosis and colonic $\mathrm{J}$ pouch-anal anastomosis $[\mathrm{J}]$. Br J Surg, 1998, 85(8):1114-1117.

[3] Gastinger I, Marusch F, Steinert R, et al. Protective defunctioning stoma in low anterior resection for rectal carcinoma [J]. Br J Surg, 2005 ,92(9): 1137-1142.

[4] Law WI, Chu KW, Ho JW, et al. Risk factors for anastomotic leakage after low anterior resection with total mesorectal excision $[\mathrm{J}]$. Am J Surg, 2000, 179(2):92-96.

[5] Machado M, Hallbook O, Goldman S, et al. Defunctioning stoma in low anterior resection with colonic pouch for rectal cancer: a comparison between two hospitals with a different policy [J]. Dis Colon Rectum, 2002,45(7) :940-945.

[6] Marusch F, Koch A, Schmidt U, et al. Value of a protective stoma in low anterior resections for rectal cancer $[\mathrm{J}]$. Dis Colon Rectum, 2002,45(9):1164-1171.

[7] Poon RT, Chu KW, Ho JW, et al. Prospective evaluation of selective defunctioning stoma for low anterior resection with total mesorectal excision [J]. World J Surg, 1999,23(5): 463-467; discussion 467-468

8] Wong NY, Eu KW. A defunctioning ileostomy does not prevent clinical anastomotic leak after a low anterior resection: a prospective, comparative study [J]. Dis Colon Rectum, 2005, 48 (11):2076-2079.

9 ] Wan XB, Pan ZZ, Chen G, et al. Meta-analysis of Postoperative Adjuvant Chemotherapy for Dukes' B Colorectal Carcinoma [J]. Ai Zheng, 2005, 24(5):600-604. [in Chinese]

[10] Rullier E, Laurent C, Garrelon JL, et al. Risk factors for anastomotic leakage after resection of rectal cancer $[\mathrm{J}]$. Br J Surg, 1998, 85(3):355-358.

[11] Antonsen HK, Kronborg O. Early complications after low anterior resection for rectal cancer using the EEA stapling device. A prospective trial $[\mathrm{J}]$. Dis Colon Rectum, 1987, 30 (8) : 579-583

[12] Fujita S, Teramoto T, Watanabe M, et al. Anastomotic leakage after colorectal cancer surgery: a risk factor for recurrence and poor prognosis [J]. Jpn J Clin Oncol, 1993, $23(5): 299-302$

[13] Petersen S, Freitag M, Hellmich G, et al. Anastomotic leakage: impact on local recurrence and survival in surgery of colorectal cancer $[J]$. Int J Colorectal Dis, 1998, 13(4) : 160163.

[14] Bucher P, Mermillod B, Gervaz P, et al. Mechanical bowel preparation for elective colorectal surgery: a meta-analysis $[\mathrm{J}]$. Arch Surg, 2004,139(12):1359-1365.

[15] Slim K, Vicaut E, Panis Y, et al. Meta-analysis of randomized clinical trials of colorectal surgery with or without mechanical bowel preparation [J]. Br J Surg, 2004,91 (9): $1125-1130$.

[16] Urbach DR, Kennedy ED, Cohen MM. Colon and rectal anastomoses do not require routine drainage: a systematic review and meta-analysis $[\mathrm{J}]$. Ann Surg, 1999,229(2) : 174180.

[17] Camilleri-Brennan J, Steele RJ. Prospective analysis of quality of life after reversal of a defunctioning loop ileostomy $[\mathrm{J}]$. Colorectal Dis, 2002,4(3):167-171.

[18 ] Gooszen AW, Geelkerken RH, Hermans J, et al. Temporary decompression after colorectal surgery : randomized comparison of loop ileostomy and loop colostomy [J]. Br J Surg, 1998, 85(1):76-79.

[19] O'Leary DP, Fide CJ, Foy C, et al. Quality of life after low anterior resection with total mesorectal excision and temporary loop ileostomy for rectal carcinoma $[\mathrm{J}]$. Br J Surg, 2001,88 (9) : 1216-1220

[20] Shellito PC. Complications of abdominal stoma surgery [J]. Dis Colon Rectum, 1998,41(12):1562-1572. 